\title{
Analysis on Enterprise Performance Evaluation System Based on EVA to Promote the Transformation of Economic Growth Mode
}

\author{
Zhifeng Jie \\ School of Accounting, Nanchang Institute of Science \& Technology, Nanchang, Jiangxi, China, \\ 330108
}

183508768@qq.com

\begin{abstract}
Keywords: EVA, Economic Growth, Performance Evaluation
Abstract. EVA plays a leading role in the promotion of economic growth mode from extensive to intensive type. EVA has obvious advantages on performance evaluation indicators in measuring enterprise performance, inhibition of short-term behavior, curbing blindly replenishment and expansion, reducing insider control. Therefore, enterprises should use performance evaluation in the implementation of EVA indicators. In order to make effect performance evaluation, we must promote the transformation of the economic growth mode by perfecting the stock market, adjusting the enterprise management structure and introducing the high quality talents.
\end{abstract}

\section{Introduction}

Although China's economy is currently in the stage of rapid development, economic growth mode is still not completely out of the extensive, and extensive growth will lead to enterprise resources which cannot be fully utilized. The change of economy growth mode is conducive to promoting the healthy and rapid economic development. EVA is an important indicator of corporate performance evaluation in promoting transformation of economic growth.

\section{The basic principles of EVA}

The ultimate goal of Enterprise is to achieve the preservation and appreciation of assets and create real value. The above goal is to focus on value management, to maximize the value of capital-oriented, to establish a scientific and reasonable, nested nest performance evaluation system, the asset management performance evaluation methods and internationalization and market integration. EVA is used for performance evaluation; EVA value is positive, the greater the value, the better Enterprise performances, managers should get more incentives; EVA value is negative, then the performance of enterprises is poor, which need to be improved.

\section{The Role of EVA in Transforming Economic Growth}

Is conducive to measuring enterprise performance and guide scientific decision-making. In recent years, some enterprises accelerate the expansion of capital, but efficiency capital is not high. The reason is mainly based on net profit indicators of financial statements information, and not deducts the cost of equity derived. However, any capital is a cost, which of equity is reflected in the opportunity cost. In addition, the calculation of EVA net operating profit after tax is adjusted according to the purpose of adjusting the impact of sound accounting, and can effectively reflect the economic reality of enterprises. Thus, EVA indicators can measure enterprise's operating performance. In addition, EVA also has the ability to select and phase out investment projects, with multiple options to choose the preferred EVA high investment projects.

Is conducive to suppress short-term behavior to reduce the profit operation. In order to obtain short-term economic benefits, managers often abandon costly, time-consuming but long-term high-yield projects, preferring short-term projects that are less costly or faster, or choose the overall net present value for early high returns. Value is low. EVA indicators tend to long-term incentives, through EVA evaluation methods guide enterprises to strengthen $\mathrm{R} \& \mathrm{D}$ investment and 
technological innovation and enhance the capacity of sustainable development. In the EVA incentive plan, the operator only creates wealth for the owner to get higher pay, which makes operators continue to pursue a higher EVA to overcome short-term behavior.

Is conducive to curb the blind increase capital and investment behavior. The use of EVA indicators for enterprise performance evaluation makes enterprise managers consider the cost of equity, which will force managers to measure cost-effectiveness in equity financing and help to curb the blind expansion of capital. At the same time, the use of EVA indicators for performance evaluation can promote the establishment of state-owned listed companies to create value for the shareholders of the concept. For firms whose capital cost is greater than the rate of return on investment (ROI), as the cost is higher and the rate of return is negative, the original shareholders will withdraw a large number of shares and cannot attract new investors to invest, or the fate of being acquired cheap. This allows managers to think like the SASAC, taking into account the benefits and risks, careful investment and avoiding the blindness of venture capital to achieve the preservation and appreciation of assets.

It will help to reduce insider control and improve the corporate governance structure. Management and shareholders of the enterprise's interests are not entirely consistent because of china's current system.it is easy to produce "insider control" phenomenon. After the formation of "insider control", enterprise managers will use their own information advantage to get rid of the SASAC control, eventually leading to low efficiency, wasting of resources and losing of assets. On the one hand, the introduction of EVA provides a good idea to solve the principal-agent problem. On the other hand, it makes managers realize that any capital is cost. For enterprises whose capital cost is more than ROI, Bankruptcy liquidation or the low price of the fate of the acquisition; at the same time, the implementation of EVA bonus banks linked to their pay, prompting managers to shift their focus to increase shareholder wealth and corporate strategic objectives up, but also will promote managers to obtain higher income. So that the use of EVA performance evaluation can effectively reduce the "insider control" phenomenon.

Is conducive to promoting the building of enterprise culture to improve employee behavior. It is known that performance evaluation is a guided institutional arrangements and the introduction of EVA performance evaluation encourages enterprises to continue the pursuit of a true value-added wealth. The continuous innovation of knowledge and technological advances as the core competitiveness of the economic era, so that enterprises achieve the desired value of EVA depending highly on the creativity of the people. Therefore, EVA will eventually further strengthen the people-oriented corporate culture.

In the EVA performance evaluation system, all the stakeholders on the same front, shareholders, creditors, managers and employees should simultaneously determine the objectives of sustainable development of enterprises with a unified vision. So that the management and the interests of employees and equity investors in line with the management and staff will be highly responsible attitude to the enterprise, the entire enterprise team with a high degree of cohesion, everyone is the masters of the enterprise.

\section{Prospect of EVA in Promoting Economic Growth}

The enterprise performance evaluation system plays a guiding role for the economic behavior of enterprises, which is conducive to standardizing the economic behavior of enterprises. EVA is the enterprise performance evaluation system, which can change our economic development rely solely on the number of growth, the scale of the expansion of the status quo. Enterprises obtain more value-added needs to continue to reduce costs through research and development; shareholders obtain greater returns and need to stand in the promotion of long-term development of enterprises from the perspective of economic decision-making.

In summary, EVA as an evaluation of enterprise performance is an important indicator, which can effectively promote economic growth mode change. In order to make the effect of performance evaluation, we must perfect EVA performance evaluation system by perfecting securities market, 
adjusting enterprise management structure, introducing high quality talents, optimizing EVA calculation, etc., and can really apply EVA to actualize and promote economic growth mode to high efficiency, to low energy consumption changes, to achieve enterprise economic growth mode from quantitative to qualitative leap.

\section{References}

[1] Zhao Zhigang. Research on Construction of Economic Value Added Analysis Monitoring System[J]. Friends of Accounting, 2016, (15) : 28-30.

[2] Yang Zhenqing,Li Xiaofen. A Summary of EVA Performance Evaluation of Listed Companies[J]. Accounting communication, 2015, (16) : 54-56.

[3] Tian Ye. Research on the Correlation between R \& D Expenditure and Firm Performance in Chinese High - tech Enterprises [D] .Beijing: Capital University of Economics and Business, 2011.

[4] Tian Jie. Application of EVA Performance Evaluation Method in Coal Listed Companies Taking Shanxi Coal Listed Companies as an Example [J] . Friends of Accounting, 2012, (2):36-38.

[5] Sheng Feng. Production Efficiency, Innovation Efficiency and SOE Reform: An Empirical Analysis of Micro - enterprise Data [J] . Industrial Economics Research.2012 , (4):37-46. 